\title{
Exploring Leibniz's Nachlass at the Niedersächsische Landesbibliothek in Hanover
}

David Rabouin (CNRS - Université de Paris, France)

The archival situation of the works of Gottfried Wilhelm Leibniz (1646-1716) is specific in comparison with many other mathematicians. Apart from the dissertation $D e$ arte combinatoria, written in his youth (1666), he never published a single treatise of mathematics during his lifetime. Around sixty articles were rendered public, though, mainly on differential calculus (and a very few on binary arithmetic), but they were often very short, allusive and sometimes even hurried. This is the case, in particular, with the famous article in which he presented his differential algorithm in 1684, the Nova methodus pro maximis et minimis - which, for this reason, was simply not understood by most of his first readers. One can already find an overview of this published material in the third volume of Louis Dutens' Gothofredi Guillelmi Leibnitii Opera omnia (Leibniz 1768). In modern editions, such as that of $\mathrm{He} ß$ and Babin (Leibniz 2011), this represents around 500 pages - to be compared to the ... 50,000 handwritten items (more than 7000 folios of mathematics) to be found in the Leibniz Nachlass (see Knobloch 2004). Brought back to the modern page format, a rough estimate is that Leibniz left around $99 \%$ of his written mathematical activity hidden during his lifetime!

Ironically enough, one can find a famous declaration in the sixth volume of Dutens' edition indicating the substantial limitations of this kind of enterprise: "who knows me only from what I published, does not know me" (Qui me non nisi editis novit, non novit, Letter to Vincent Placcius, 21 february $/ 2$ march 1696, Dutens VI, 1, 65). Indeed, it was already a well-known fact at the time. Just a few years before, Diderot wrote in the Encyclopédie: "Perhaps no man has ever read so much, studied so much, meditated so much, written so much as Leibnitz; yet there is no body of work by him; it is surprising that Germany, to which this man alone does as much honour as Plato, Aristotle and Archimedes together do to Greece, has not yet collected what has come out of his pen" (Diderot 1765, 379, as quoted in Poser 2012). "Jamais homme ... n'a plus écrit": considering the nearly 100,000 folios and 20,000 letters which are kept in the department of manuscripts of the Gottfried Wilhelm Leibniz - Bibliothek Niedersächsische Landesbibliothek (GWLB) in Hanover, it does not seem to be too much of an exaggeration.

Soon, people felt compelled to look into the unpublished material, but mathematics was not well served. What one finds in the Raspe edition (Leibniz 1765) is only about logic, and even the Erdmann edition (Leibniz 1840) still only contains the logical calculi as a new topic that could be related to mathematics (as well as some methodological papers related to the project of a scientia generalis) ${ }^{1}$. Nothing, for example, on the famous project of Analysis situs, which was known through some allusions in published letters. Interestingly enough, mathematicians of the time thought that this material was lost and that their task was to reconstruct it - in the same way that early modern authors attempted to revive lost treatises from antiquity by some kind of divinatio (Diophantus, Apollonius redivivus...). As is well known, this is the way in which Grassmann or Moebius publicly presented their own projects of new geometrical calculi, which they considered as vindicating Leibniz's original ideas. It is only with Gerhardt's edition of the Mathematische Schriften (Leibniz 1849-1863), starting in the middle of the 19th century, that some of the hitherto unknown mathematical material was progressively discovered for the first time. This was especially the case with volume 5 (1858) containing texts related to "Characteristica Geometrica. Analysis Geometrica propria. Calculus situs", and with volume 7 (1863) dedicated, amongst other topics, to "Initia mathematica" or "Mathesis universalis". In the wake of these editions, authors such as Louis Couturat called for a reappraisal of Leibniz's ideas, in which the work in logic and mathematics should be put at the core of the entire philosophical system (Couturat 1901). Couturat himself completed Gerhardt's work in 1903 with his Opuscules et Fragments inédits, in which he gave access to many other unpublished mathematical works (Leibniz 1903).

From this overall picture, one might get the impression that for a century or so, we have been in possession of a good overview of Leibniz's unpublished work in mathematics. But this is far from true: in fact, to this day, more than half of Leibniz's mathematical work still remains completely unpublished. Moreover, when one looks at the published half, typically the editions of Gerhardt and Couturat, one soon realises that they were not accomplished according to modern scientific standards. This last point may seem incidental. We do not always need to have all the philological details of variants and

\footnotetext{
1 It played a very important role in the history of logic as can be seen in the fact that Frege quoted this edition at the beginning of his Grundlagen der Arithmetik (1884) to vindicate an "analytic" reading of mathematical statements, which he attributed to Leibniz. On the edition of Leibniz mathematical texts in the 18th century, see Probst 2016.
} 
marginalia to read a text. For the layperson who is foremostly interested in the content, such critical apparatus may even sometimes appear as an impediment to reading. The problem is unfortunately much deeper, because some texts edited by Gerhardt and Couturat have turned out to be mere artefacts. Let me give two talking examples of this difficulty taken from two of the main topics presented in volume 7 of Gerhardt's edition, namely initia mathematica and mathesis universalis:

- The very first text of volume 7 of the Mathematische Schriften is a much-celebrated piece of work on the "Metaphysical Foundations of Mathematics" (Initia rerum mathematicarum metaphysica). It has given rise to a wealth of commentaries not only from philosophers, but also from scientists, since Leibniz gives in it his definitions of time and space as pure systems of relations. The text is not easy to provide commentary on due to its non-linear structure. Many topics mentioned at the beginning are taken up again, in a slightly different manner, later in the text. When one looks at the manuscript, this comes as no surprise: as was discovered by Vincenzo De Risi when exploring the corpus related to Analysis situs (De Risi 2007), Gerhardt simply copied two different texts from two different periods and placed them side by side! The text, as published in the Mathematische Schriften, simply does not exist as such. It is Gerhardt's invention.

- Let us now take a look at another celebrated text: the Elementa nova matheseos universalis. It was published for the first time by Couturat in 1903 and also gave rise to a wealth of commentaries. It is one of the rare places where Leibniz expounded his programme of "new" universal mathematics (as opposed to Descartes', still centred on magnitude and algebra). Couturat's text is full of dots indicating lacunae in the manuscript (as specified at the beginning of the book: "les points espacés indiquent les lacunes de notre copie"). Yet, when one looks at the manuscript, one can easily see that there are no lacunae in it. Dots stand for passages Couturat did not take the trouble to copy. Maybe because they did not match the kind of interpretation he wanted to suggest! Indeed, since Couturat wanted to insist on the fact that Leibniz had a purely formal approach to what are now called "equivalence relations" and detailed their formal properties, he just cut the passage in which Leibniz derived this description from phenomenological considerations (according to Leibniz, geometrical relations are induced by the way in which we may or not be able to "discern" objects in perception). It was not until 1999, when the first scientific edition of the philosophical texts from the 1680s was issued, that scholars interested in this topic could read for the first time what Leibniz's programme really was.

There are many other examples showing that what we call "Leibniz's mathematical texts" is not a simple matter of one of the so-called Leibniz "editions". One reason is, of course, the enormous amount of papers preserved in the GWLB and the temptation that naturally arises for the editors confronted with such an overwhelming wealth of material to classify it in advance, neglect the "innocuous" variants or "unimportant" notes and select what they consider "interesting" passages, etc. Another reason is that the archive itself was catalogued (in the 19th century by Eduard Bodemann) in a very rough fashion: folios were only sorted according to general topics (sometimes as general as "mathematics") or vague similitude, and with no particular consideration of time period, precise relationship between the documents, etc. Hence the project, which did not arise until the beginning of the 20th century, to directly confront the difficulty and publish all of this material in chronological order and with all the variants. This is the origin of the so-called "Akademie Edition", which now constitutes the standard for any rigorous access to the Leibniz texts (Leibniz 1923-).

The first volume of the first series dedicated to the political and historical correspondence appeared in 1923 (Allgemeiner politischer und historischer Briefwechsel), soon to be followed, in 1926, by the first volume of the second series dedicated to the philosophical letters (Philosophischer Briefwechsel). When it came to the third series, however, the one dedicated to the mathematical correspondence, things became more complicated due to the expertise necessitated by such an enterprise (in Latin, in philology, in history of science and, of course, in mathematics). Dietrich Mahnke was the first to be in charge of this task and had completed almost half of it when he died unexpectedly in 1939. The work was then taken over by Joseph Ehrenfried Hofmann and was first published three years after his death in ... 1976. At that time, the publication of the mathematical texts themselves (series VII) had not yet even begun! It is only with the efforts of Eberhard Knobloch that this gigantic enterprise could really start in 1976 (see Knobloch 2018 for an account of this enterprise). As a result, the first volume of the mathematical series, gathering texts of arithmetic (number theory), (elementary) geometry and algebra from the period of Leibniz's stay in Paris (1672-1676), did not appear until ... 1990.

One of the reasons why Knobloch was (and still is!) enthusiastic about this thankless and arduous task was that he already knew that the papers left by Leibniz contained many mathematical treasures. He provided a first example in his $\mathrm{PhD}$, in which he documented the many works Leibniz had done on combinatorics, in particular on what is now called symmetric functions, and his remarkable achievements in the constitution of determinant theory (these works were published as Knobloch 1973, Knobloch 1976 and Knobloch 1980). But there were many other treasures awaiting publication. One of them was a treatise on quadratures, which Leibniz wrote at the end of his Parisian sojourn under the title Quadratura arithmetica circuli ellipseos et hyperbolae. This text had been known for some time, because Leibniz often refers to it in his correspondence. Lucie Scholtz already provided a partial translation in her PhD (Scholtz 1934). Yet it was not until 1993 that a complete edition appeared (Leibniz 1993). Ten years before, the philosophical papers from the Parisian stay were published in volume 
3 of series VI of the Akademie Edition. They gave access to many reflections Leibniz developed at the time of the creation of his differential algorithm on infinitely small and infinitely great quantities (see Arthur 2001 for an English translation). The result of these publications was a complete transformation of the prevailing view on the position Leibniz held on the foundation of infinitesimal techniques. While it was previously believed that his conception of the subject was somewhat fuzzy and that his recourse to the vocabulary of the "fictions utiles" was just a convenient way to escape the foundational difficulties raised by his opponents in the 1690s, it now appears that this "fictionalist" strategy was already achieved by 1676 (with no opponents to confront it!) and referred to some precise and rigorous proofs (for the detail of these proofs see Knobloch 2002; Rabouin 2015).

Eight volumes of the mathematical correspondence (series III) and seven volumes of the mathematical texts (series VII) have now appeared. Since the 2000s, the various volumes have been accessible as a digital edition as well as in print (https://leibnizedition.de/). Eberhard Knobloch, first assisted by Walter Contro (who passed away in 2017), was then joined by Nora Gädeke and later Siegmund Probst. A small team was progressively constituted for the edition of mathematical texts in the Leibniz Archiv in Hanover (see Knobloch 2018, 32, for a list of the contributors to the various volumes). Yet, this only gives access to the texts written in Paris and at the beginning of the stay in Hanover (1672-1677; recall that Leibniz died nearly 40 years later, in 1716). The classification of Leibniz's manuscripts made by Bodemann in the 19th century (for mathematics, essentially in the rubric noted LH XXXV), as well as the work done since, have led to an estimate of about ... 22 mathematical volumes remaining to be published for the period 1677-1716 (the LH XXXV group represents around 7000 folios and each volume of the Akademie Edition generally gathers around 200 of these folios, which corresponds to 800 published pages in quarto). As we recall, only $25 \%$ of these texts have already been published. For half of them, there was simply no entry in the catalogue and for the other half, no precise indication of content. From 2012 to 2014, the data corresponding to the Leibnizian mathematical manuscripts was entered into the central publishing catalogue and preliminary dating work was undertaken by the Hanover publishers (http://mdb.lsp.uni-hannover. de/). The digitisation of the mathematical manuscripts was undertaken in parallel and went online in September 2016 - a resource of invaluable help for scholars working in the domain (http://digitale-sammlungen.gwlb.de/ index.php?id=7).

Are there other mathematical treasures awaiting us in the ocean of unpublished manuscripts? Without a doubt! In 2010, a study group was launched in France, in close collaboration with German colleagues from the Leibniz Archiv, to analyse these unpublished manuscripts more systematically from a historical and epistemological point of view. It started with a modest goal: editing Leibniz texts on mathesis universalis, a topic I have already mentioned as having been mistreated by Couturat (and
Gerhardt) and for which the corpus is fortunately not too vast. This resulted in the volume (Leibniz 2018), in which a new interpretation of the topic was proposed. In 2017, funding was obtained from the French Agence Nationale de la Recherche in order to develop these activities in close connection with the work done by Leibniz editors in Hanover ${ }^{2}$. The work was greatly helped by the advances made by the previous generations of scholars. Besides Knobloch, Siegmund Probst and their team in Hanover, one could mention work done by Javier Echeverría on analysis situs and geometry (which was (partially) published in Leibniz 1995), by Enrico Pasini on the foundations of differential calculus (which was (partially) published in Pasini 1993), by Emily Grosholz on the foundation of arithmetic (Grosholz and Yakira 1998) or by Mary Sol De Mora Charles on games (De Mora Charles 1992).

One could start with the last topic, since it shows nicely how many questions still remain open for the researchers exploring Leibniz's mathematical Nachlass. In 1992, De Mora Charles transcribed some unpublished mathematical texts on games, including a description of a game created by Leibniz: the "inverse solitary" (in which one has to fill the board instead of emptying it). This is an interesting piece, because Leibniz takes a similar example in one of his metaphysical texts from the same period, the famous De rerum originatione radicali (1697). In it, he compares God's act of creation with "certain games in which all the places on the board are to be filled according to definite rules, but unless we use a certain device, we find ourselves blocked out, in the end, from the difficult spaces and compelled to leave more places vacant than we needed or wished to" (Leibniz 1849-1863, t. VII, 303; English translation in Loemker 1989, 487). But there is more, since at the end of the text transcribed by De Mora Charles, Leibniz claims that one could treat this kind of game like "a" geometry. Notice that he does not speak of a geometrical treatment of the game, but of the fact that the game itself can be seen as "a kind of geometry". Accordingly, Leibniz claims, one could describe in it an equivalent of "straight lines, lines composed of lines, and simple and

\footnotetext{
2 ANR Mathesis, Édition et commentaires de manuscrits mathématiques inédits de Leibniz (2017-2021), $\mathrm{N}^{\circ}$ ANR17-CE27-0018-01 AAP GENERIQUE 2017. Members: Jean-Pascal Alcantara (ESPE/Université de Bourgogne), Andrea Costa (Centre Jean Pépin-UMR 8230), Valérie Debuiche (AMU, Centre Granger-UMR 7304, investigator for Aix-Marseille), Vincenzo De Risi (CNRS, SPHERE-UMR 7219), Baptiste Mélès (Archives Poincaré-UMR 7117), Anne Michel-Pajus (IREM, Paris Diderot), David Rabouin (CNRS, SPHERE-UMR 7219, principal investigator) \& Claire Schwartz (University Paris Ouest, Nanterre). The project also includes four post-doctoral positions: Sandra Bella, Mattia Brancato, Davide Crippa and Miguel Palomo. It also includes three PhD: Morgan Houg, Vincent Leroux, Arilès Remaki.

3 "Pour rediger ce jeu en art, il faut le traiter comme une geometrie particuliere, par elemens. Il faut le moyen de former des lignes droites; des lignes cornposes de droites, et des figures simples et composees, qui sont toujours composees de lignes droites“ (De Mora Charles 1992,155).
} 
composite figures" 3 . Such an abstract understanding of what "a geometry" could be, "straight line" being here a purely abstract object and figures being obtained in a combinatorial way, is striking for the modern reader and invites further inquiries into the Nachlass.

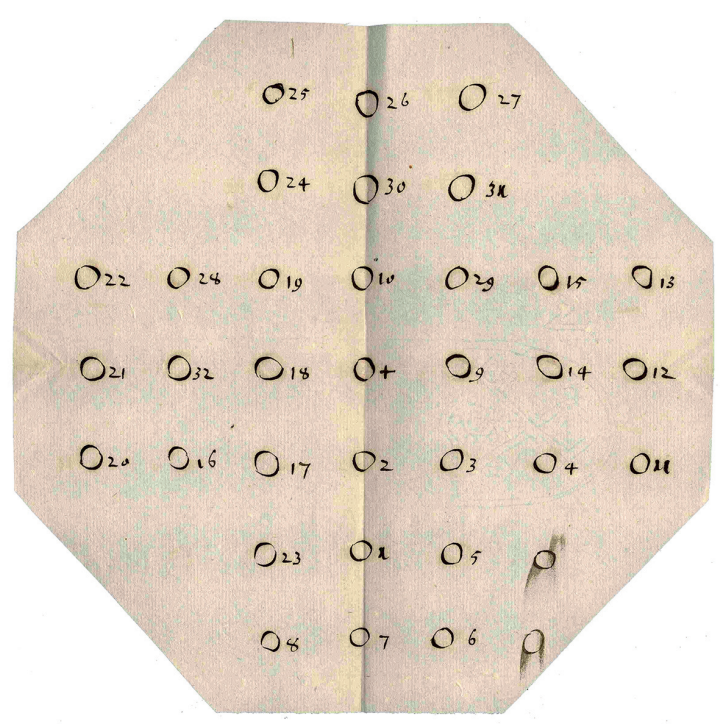

Diagram for the mathematical treatment of the Solitaire ${ }^{4}$.

Interestingly enough, Vandermonde may have had some insight into this background when tackling the subject of the "géométrie de situation". In the volume of Histoire de l'Académie Royale presenting his Mémoire on this topic (Histoire 1771), it is said, just after evoking the Leibnizian Geometria situs: "This idea of Leibniz has so far been very much neglected. I know in this kind only some Essays that Leibniz himself gave on the Game of Solitaire, and the Research of Mr. Euler on the walk of the knight in chess (...). M. Vandermonde endeavoured particularly to find, for this kind of analysis, a simple notation, and which could facilitate the calculations". Vandermonde's paper is about the way one can compute on knots, braids or the moving of a piece in chess - topics apparently unrelated to the Leibnizian project of analysis situs. Yet Leibniz mentions in a famous letter to Montmort that games could be classified into three types, the first one being about situs (Leibniz 1875-1889, vol. $3,668)$. This is precisely where he mentions his work on the Solitaire ${ }^{5}$. Moreover, one finds in Leibniz's Nachlass notes on ars textoria (see illustration below), which he discovered by reading Joachim Jungius and in which he points to his own project of a characteristica situs. These notes still await study and a more systematic exploration of the connection between games, knots and analysis situs.

4 Gottfried Wilhelm Leibniz Bibliothek, Niedersächsische Landesbibliothek, Leibniz-Handschriften zur Technica, LH 38, fol. 195 v. http://digitale-sammlungen.gwlb.de/ resolve id $=00068537$

5 Vincent Leroux is completing a $\mathrm{PhD}$ thesis on the topic of games in Leibniz's ideas in the framework of our ANR project.

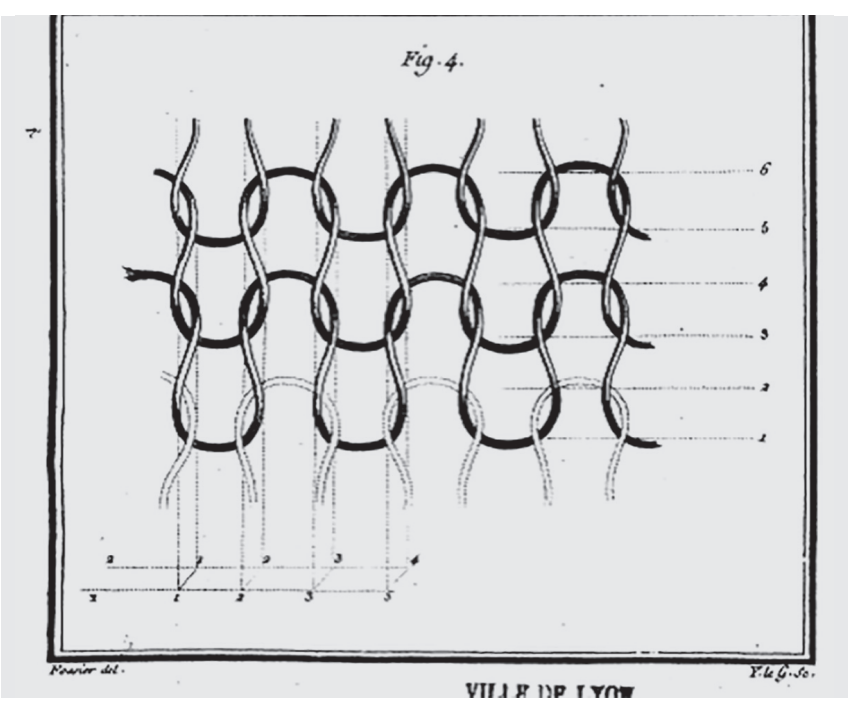

Vandermonde 1771

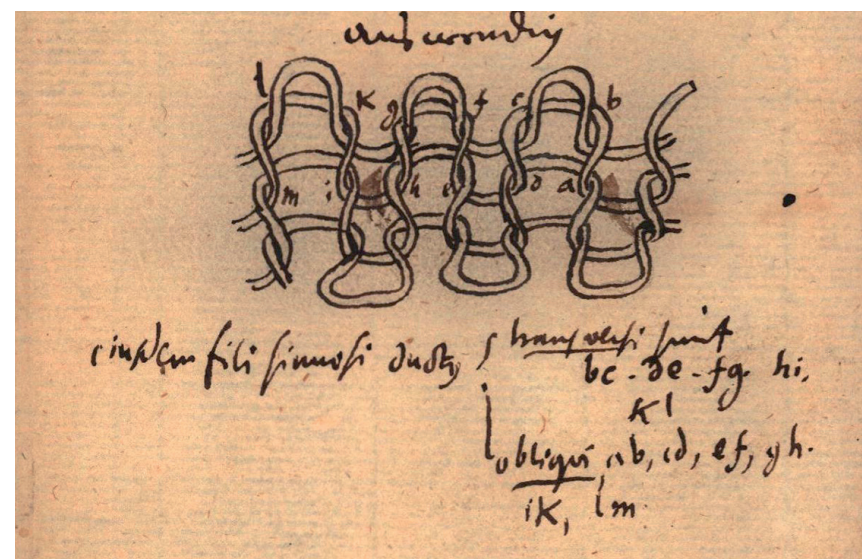

From Leibniz's notes on ars textoria. ${ }^{6}$

This gives an example of the complexity involved in working with Leibniz's manuscripts and the dangers of selecting in advance where to look and what to look for. Although it was obvious for some of Leibniz's heirs that the work on analysis situs had something to do with his work on games and on geometria sartorum - as was also pointed out by Vacca when undertaking his own research on the geometry of folding, on the basis of one of Leibniz's unpublished manuscript (Friedman 2018,320) - this knowledge was lost at some point in history. As a consequence, this kind of research is now classified outside of the mathematical series, amongst the "technical" texts (series VIII: Naturwissenschaftliche, Medizinische und Technische Schriften).

More generally, many aspects of the vast project of analysis situs still remain to be explored in greater detail. It was known, for example, since Echeverría and Parmentier's edition (Leibniz 1995, 272) that Leibniz worked on geodesics (lineae minimae) on the sphere and the cylinder quite early on, but Vincenzo de Risi found

6 Gottfried Wilhelm Leibniz Bibliothek, Niedersächsische Landesbibliothek, Leibniz-Handschriften zur Technica, LH 38, fol. 38r. http://digitale-sammlungen.gwlb.de/ resolve id $=00068537$ 
later texts in which Leibniz goes as far as posing the general problem of geodesics on curved surfaces (De Risi 2007, Appendix 6 and 7, 592-595). This question was taken into broader consideration. Indeed, if linea minima serves as a definition for "straight line", as has been proposed by some authors since antiquity, this would mean that one could have "straight lines" (in this case great circles) that are parallel (in the sense of making right angles with another line) and still intersecting - a fact which struck Leibniz very early as problematic for the definition of parallel lines. Following this thread, De Risi has uncovered very rich material related to several attempts at proving the parallel postulate. In these texts one can see Leibniz fighting against his own insight into the possibility of other "geometries". A very interesting result is that the philosopher realised that he could not provide such an exclusion by purely logical means (i.e. by resorting to the sole principle of contradiction) and was bound to invoke "superior principles", as he calls them, such as the "principle of sufficient reason" (De Risi 2016).

Another topic on which my colleagues Valérie Debuiche and Mattia Brancato are now working is Leibniz's studies on mathematical perspective. Like in the case of games, an interesting aspect of these unpublished studies is that they relate to a theme often mentioned in his metaphysics (each individual substance, or monads, is a "point of view" on the universe like various perspectives of the same town). Yet, the works Leibniz dedicated to scientia perspectiva are still not published, for reasons comparable to what happened with ars textoria: they belong, in some part, to technical papers which were not included in the mathematics series (see, for example, the notes on Bosse, Desargues, Aleaume and Dubreuil contained in the first volume of the technical series VIII; Debuiche 2013) ${ }^{7}$. One could also mention the many studies Leibniz dedicated to the role of tractional motion in the construction of curves and of which a first overview (for the beginning of the Hanoverian period) can now be accessed through the recent publication of the volume 7 of the series VII (http://www.gwlb.de/Leibniz/Leibnizarchiv/Veroeffentlichungen/VII7.pdf). As Davide Crippa has shown, this constituted a constant preoccupation for Leibniz, since he saw in tractional motion a way of enlarging the Cartesian standard of constructions by "continuous motion" and accordingly what could constitute a proper definition of what a "geometrical" curve was - as contrasted to Descartes' identification of "geometrical" to "algebraic" (see Crippa 2020).

But geometry is not the only topic in which many of Leibniz's gems are still waiting to be excavated. As pointed out in (Knobloch 2004), Leibniz dedicated some very interesting studies to the distribution of prime numbers during his Parisian stay, a topic which, at the time, was

\footnotetext{
7 With our colleagues in Hanover we have prepared a preprint edition, which can be accessed at the following address: http://www.gwlb.de/Leibniz/Leibnizarchiv/Veroeffentlichungen/PreprintsReiheVII.htm
}

not of particular interest to mathematicians. In this context, he devised various diagrammatic representations with the hope of seeing a pattern emerging and by the same token developing a form of geometry of numbers - another brilliant and original idea for the time (Knobloch 2004) ${ }^{8}$.

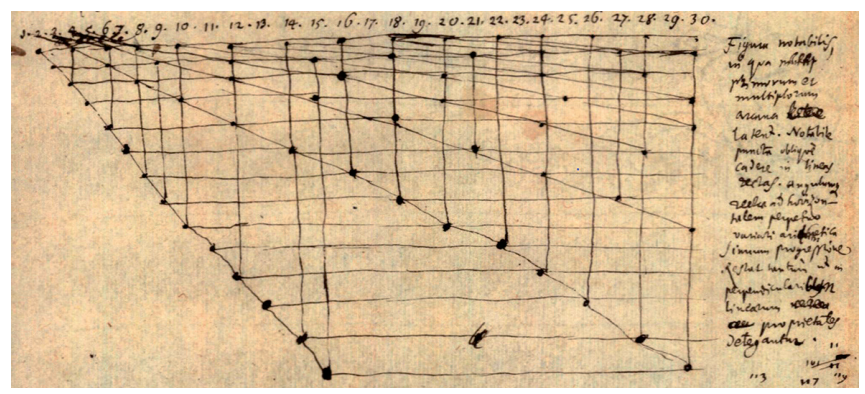

A study on the distribution of prime numbers. ${ }^{9}$

Let me finish by mentioning the example of Leibniz's work on the axiomatic foundations of algebra. As has been known since the beginning of the 19th century, Leibniz may be considered the first author to have developed formal axiomatics for logical calculi (as testified to in particular by the remarkable Non inelegans specimen demonstrandi in abstractis from 1687, which was already published by Erdmann and made such a great impression on Frege). For a long time, it was thought that he developed these axiomatic systems as a generalisation of his research in arithmetic and algebra (see, for example, Lenzen 1989). Thanks to a better dating of the manuscripts, we now know that it was the other way round: Leibniz first developed formal calculi for logic (and, more generally, for mereological relations) at the end of the 1680s and then turned to algebra. This evolution may be related to the fact that he stumbled upon what we now call the "idempotence" axiom as characterising logical operations - quite a remarkable result in and of itself. By the same token he realised that, contrary to his initial hopes, it was not possible to have one abstract calculus holding at the same time for "notions" and for "magnitudes" (Pajus and Rabouin 2017). This gives an interesting context for the study of the attempts he made to edify axiomatic foundations for algebra around 1700 . In particular, it offers a new context for the reading of the famous derivation of " $2+2=4$ " as a chain of definitions and substitutions (plus one axiom for equality), which Frege took as a basis for vindicating the idea that mathematical statements (at least on natural numbers) were purely logical statements (Leibniz 2018, 169-180).

\footnotetext{
8 See also the PhD Morgan Houg just defended (December 2019) on Arithmetic during the Parisian Stay (soon to be accessible here: http://www.theses.fr/s180861). Arilès Remaki is also completing a $\mathrm{PhD}$ in which he also studies in great detail the role of diagrammatic representations for combinatorial thinking in Leibniz.

9 Gottfried Wilhelm Leibniz Bibliothek, Niedersächsische Landesbibliothek, Leibniz-Handschriften zur Mathematik, LH 35, 4, 17, fol. 5v. http://digitale-sammlungen.gwlb.de/ resolve $? \mathrm{id}=00068014$
} 
Indeed, as was already noticed by Emily Grosholz, the derivation of " $2+2=4$ " should be inserted in the context I just recounted and in which the central concept is not that of natural numbers, but that of magnitude (Grosholz and Yakira 1998). Accordingly, the "logicist" reading of these texts appears to be a truncated one. Many manuscripts from this period are still waiting to be transcribed and studied in more detail. Amongst them, I chose one which gives an idea of the kind of mathematics Leibniz achieved at the end of his life and which looks so familiar to the modern reader, although it was a kind of oddity in the context of the mathematics of the time. It gives a list of axioms in which any mathematician today would recognise the commutativity of addition and multiplication, the role of neutral elements ( 0 for addition, 1 for multiplication), the existence of inverse for both operations and the distributivity of the second over the first.

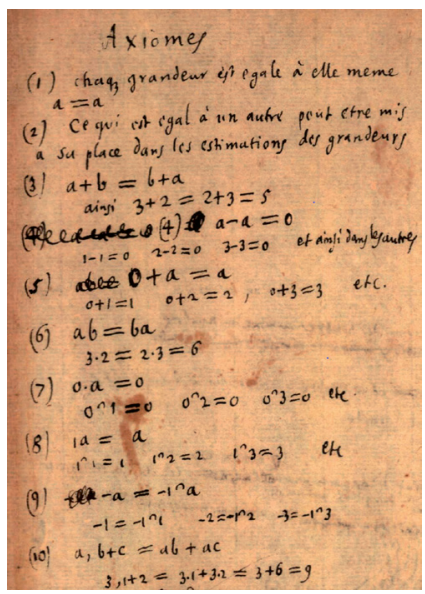

Elements du calcul. ${ }^{10}$
Axiomes

(1) chaque grandeur est égale à elle même $a=a$

(2) ce qui est égal à un autre peut être mis a sa place dans les estimations des grandeurs

(3) $a+b=b+a$

(4) $a-a=0$

(5) $0+a=a$

(6) $a b=b a$

(7) $0 \cdot a=0$

(8) $1 a=a$

(9) $-a=-1^{-} a$

(10) $a, b+c=a b+a c$
Due to space constraints, I did not transcribe the numerical examples, nor did I reproduce item (11), which characterises the multiplicative inverse of any element by the axiom $\frac{a}{a}=1$ (the next item in the list making it clear that Leibnitz interprets $\frac{a}{a}$ as $a \cdot \frac{1}{a}$ although he should have stated that $a$ be different from 0 ). This is quite a remarkable way of characterising what will later be called an algebraic "structure". Although this is certainly not what Leibniz had in mind (one would not find any "structural" theorems in these texts), the kind of formal presentation which he reached at this occasion is nonetheless striking and had no equivalent at the time (and, more generally, before the 19th Century).

These are just a few examples of the treasures waiting to be studied in Leibniz's mathematical Nachlass. Let us hope more young researchers, historians as well as mathematicians, will be tempted to visit this temple in the future and contribute to the long-lasting effort of transcribing them. Leibniz, who lived just after the Thirty Years' War (he was born two years before the Peace of Westphalia) was a strong supporter of a political and sci-

${ }^{10}$ Gottfried Wilhelm Leibniz Bibliothek, Niedersächsische Landesbibliothek, Leibniz-Handschriften zur Mathematik, LH 35, 4, 12 fol. 2r. http://digitale-sammlungen.gwlb.de/ resolve?id=00068009 entific Europe, in which he saw the only way to overcome the dangers of religious extremism. One way to revive his legacy is certainly to maintain this spirit of European cooperation in science and the humanities.

\section{References}

Arthur 2001: Richard T. W. Arthur, The labyrinth of the continuum: Writings on the continuum problem, 1672-1686, New Haven: Yale University Press, 2001.

Couturat 1901: Louis Couturat, La Logique de Leibniz, Paris: Alcan, 1901.

Crippa 2020: David Crippa, "One String Attached: Geometrical Exactness in Leibniz's Parisian Manuscripts", Leibniz and the Structure of Sciences. Modern Perspectives on the History of Logic, Mathematics, Dynamics, ed. V. De Risi, Cham: Springer, 2020 (coll. Boston Studies in Philosophy and History of Science): 203-252.

Debuiche 2013: Valérie Debuiche, "Perspective in Leibniz's invention of Characteristica Geometrica: The problem of Desargues' influence", Historia Mathematica, vol. 40, Issue 4, 2013, 359-385.

De Risi 2007: Vincenzo De Risi, Geometry and Monadology, Dordrecht: Springer, 2007.

De Risi 2016: Vincenzo De Risi, Leibniz on the Parallel Postulate and the Foundations of Geometry, Cham: Springer, 2016.

Diderot 1765: Denis Diderot, article LÉIBNITZIANISME ou PHILOSOPHIE DE LÉIBNITZ, Encyclopédie ou Dictionnaire raisonné des sciences, des arts et des métiers, Paris: Briasson, David l'Aîné, Le Breton, Durand, vol. IX (1765), p. 369-379.

Folkerts 2008: Menso Folkerts, "Die Leibniz-Edition zwischen Wissenschaft und Politik: zur Geschichte der mathematisch-naturwissenschaftlichen Reihen", Kosmos und Zahl, ed. Hartmut Hecht et al., Stuttgart: Franz Steiner, 2008: 23-45.

Friedman 2018: Michael Friedman, A History of Folding in Mathematics: Mathematizing the Margins, Basel: Birkhäuser, 2018 (Science Networks. Historical Studies, Band 59).

Grosholz and Yakira 1998: Emily Grosholz and Elhanan Yakira, Leibniz's Science of the Rational, Stuttgart: Franz Steiner, 1998 (Studia Leibnitiana, Sonderheft 26).

Knobloch 1973: Eberhard Knobloch, Die mathematischen Studien von G.W. Leibniz zur Kombinatorik, Wiesbaden: Franz Steiner, 1973 (Studia Leibnitiana Supplementa, Band XI)

Knobloch 1976: Eberhard Knobloch, Die Mathematischen Studien von G.W. Leibniz zur Kombinatorik. Textband, Stuttgart: Franz Steiner, 1976 (Studia Leibnitiana Supplementa, Band XVI).

Knobloch 1980: Eberhard Knobloch, Der Beginn der Determinantentheorie. Leibniz nachgelassene Studien zum Determinantenkalkül. Hildesheim: Gerstenberg, Arbor Scientiarum, Volume 2, 1980.

Knobloch 2004: Eberhard Knobloch, "Leibniz and the use of manuscripts: Text as a process", in History of science, history of text, ed. K. Chemla, Dordrecht: Springer, 2004: 51-79.

Knobloch 2018: Eberhard Knobloch, "Notes on Series VII and VIII of the Leibniz-Edition", Mathematical Correspondences and Critical Editions. Trends in the History of Science, ed. M. Borgato, E. Neuenschwander, I. Passeron, Cham: Birkhäuser, 2018, 27-47.

Leibniz 1765: Oeuvres philosophiques, latines et françaises, de feu M. de Leibnitz, publiées par M. Rud. Eric. Raspe, avec une préface de Mr. Kästner. Amsterdam et Leipzig: J. Schreuder, 1765.

Leibniz 1768: Gothofredi Guillelmi Leibnitii Opera omnia, ed. L. Dutens, Geneva: apud fratres de Tournes, 1768.

Leibniz 1840: God. Guil. Leibnitii Opera Philosophica quae exstant latina gallica germanica omnia, ed. J. E. Erdmann,Berlin: Eicher, 1840

Leibniz 1849-1863: Leibnizens Mathematische Schriften, ed. C.I. Gerhardt, Berlin: A. Asher and Halle: H.W. Schmidt, 1849-1863.

Leibniz 1875-1889: Gottfried Wilhelm Leibniz, Die philosophischen Schriften, ed. C. Gerhardt, Halle; H. W. Schmidt, 1875-1889.

Leibniz 1903: Opuscules et Fragments inédits de Leibniz: extraits des 
manuscrits de la Bibliothèque royale de Hanovre, ed. Louis Couturat, Paris: Alcan, 1903.

Leibniz 1923: Gottfried Wilhelm Leibniz, Sämtliche Schriften und Briefe, herausgegeben von der Berlin-Brandenburgischen Akademie der Wissenschaften und der Akademie derWissenschaften zu Göttingen, Reihe 1-8, Darmstadt, Leipzig, Berlin, 1923-.

Leibniz 1993: Gottfried Wilhelm Leibniz, De quadratura arithmetica circuli ellipseos et hyperbolae cujus corollarium est trigonometria sine tabulis, critical edition and commentary by Eberhard Knobloch. Abhandlungen der Akademie der Wissenschaften in Göttingen, Mathematisch-physikalische Klasse 3. Folge, Nr. 43, Göttingen: Vandenhoeck \& Ruprecht, 1993.

Leibniz 1995: Gottfried Wilhelm Leibniz, La Caractéristique géométrique, texte établi, introduit et annoté par Javier Echeverría, traduit, annoté et postfacé par M. Parmentier, Paris: Vrin, 1995.

Leibniz 2011: Gottfried Wilhelm Leibniz, Die mathematischen Zeitschriftenartikel, ed. von Heinz-Jürgen $\mathrm{He} ß$ u. Malte-Ludolf Babin, Hildesheim: Olms, 2011.

Leibniz 2018: Gottfried Wilhelm Leibniz, Mathesis universalis. Écrits sur la mathématique universelle, textes traduits, présentés et annotés sous la direction de David Rabouin, Paris: Vrin, 2018.

Lenzen 1989: Wolfgang Lenzen, "Arithmetical vs. 'Real' Addition - A Case Study of the Relation between Logic, Mathematics, and Metaphysics in Leibniz", Leibnizian Inquiries, ed. N. Rescher, Lanham: University Press of America, 1989: 149-157.

Loemker 1989: Gottfried Wilhelm Leibniz, Philosophical Papers and Letters, ed. Leroy E. Loemker, Dordrecht: D. Reidel, 1969.

Mora Charles 1992: Maria Sol de Mora Charles, "Quelques jeux de hazard selon Leibniz (manuscrits inédits)". Historia Mathematica 19 (1992): 125-157.

Pajus and Rabouin 2017: Anne Michel-Pajus and David Rabouin, "Logica Mathematica: Mathematics as Logic in Leibniz", Leibniz and the Dialogue between Sciences, Philosophy and Engineering, 1646-2016. New Historical and Epistemological Insights, ed. R. Pisano and al, London: The College's Publications, 2017:309-330.

Pasini 1993: Enrico Pasini, Il reale e l'immaginario. La fondazione del calcolo infinitesimale nel pensiero di Leibniz, Torino: Edizioni Sonda, 1993.
Poser 2012: Hans Poser, “Die Frühphase der Leibniz-Edition”, Komma und Kathedrale. Tradition, Bedeutung und Herausforderung der Leibniz-Edition, ed. Wenchao Li, Berlin: Akademie-Verlag, 2012, 23-35.

Probst 2016: Siegmund Probst, "Die postume Edition des mathematischen Schaffens von Leibniz und ihre Rezeption bis Ende des 18. Jahrhunderts", Theatrum naturae et artium - Leibniz und die Schauplätze der Aufklärung, ed. Daniel Fulda, Pirmin StekelerWeithofer, Stuttgart/Leipzig: S. Hirzel Verlag, 2019, 245-254.

Rabouin 2015: David Rabouin, "Leibniz's Rigorous Foundations of the Method of Indivisibles or How to Reason with Impossible Notions", Seventeenth-Century Indivisibles Revisited, ed. V. Jullien, Cham: Birkhäuser, 2015 (Science Networks. Historical Studies, Vol. 49): 347-364.

Scholtz 1934: Lucie Scholtz, Die exakte Grundlegung der Infinitesimalrechnung bei Leibniz, Marburg, 1934

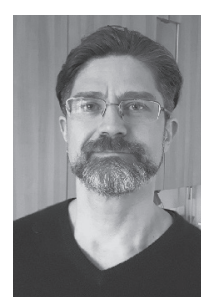

David Rabouin is a Senior Research Fellow (CR1) at the French National Centre for Scientific Research (CNRS), in the research group SPHERE (UMR 7219, CNRS - Université de Paris). His interest is in the history of philosophy and mathematics in early Modern Times, with special focus on Descartes and Leibniz. He is the author of Mathesis universalis. L'idée de «mathématique universelle» d'Aristote à Descartes, Paris, P.U.F., coll. «Épiméthée», 2009 and, in collaboration with the 'Mathesis' Group, of Leibniz. Ecrits sur la mathématiques universelle, Paris, Vrin, 2018. With K. Chemla and R. Chorlay, he co-edited the The Oxford Handbook of Generality in Mathematics and the Sciences (Oxford University Press, 2017). 